\title{
Recurrent Diabetic Ketoacidosis following Bariatric Surgery: The Role of Micronutrients
}

\author{
Philip Moseley ${ }^{1}$ Mohamed H Ahmed ${ }^{1,2}$ Henry Owles ${ }^{1}$ \\ ${ }^{1}$ Department of Medicine, Milton Keynes University Hospital NHS \\ Foundation Trust, Eaglestone, Milton Keynes, Buckinghamshire, \\ United Kingdom \\ 2Department of Medicine and HIV Metabolic Clinic, Milton Keynes \\ University Hospital NHS Foundation Trust, Eaglestone, Milton \\ Keynes, Buckinghamshire, United Kingdom
}

\begin{abstract}
Address for correspondence Mohamed Hassan Ahmed, MBBS, PhD, SCE, Department of Medicine and HIV Metabolic Clinic, Milton Keynes University Hospital NHS Foundation Trust, Eaglestone, Milton Keynes MK6 5LD, Buckinghamshire, United Kingdom (e-mail: mohamed.hassan-ahmed@mkuh.nhs.uk).
\end{abstract}

\begin{abstract}
Keywords

- thiamine

- bariatric surgery

- diabetes
\end{abstract}

\section{Background}

Bariatric surgery is widely used in the treatment of morbid obesity. The benefit extends to treatment of type 2 diabetes, nonalcoholic fatty liver disease, hypertension, and dyslipidemia. ${ }^{1}$ The Swedish Obese Subjects studies showed that bariatric procedures have a long-term effect and are associated with a significant improvement in quality of life and reduction in mortality related to cardiovascular disease and cancer., ${ }^{2,3}$ In a systemic review and meta-analysis by Park et al, they showed that bariatric surgery was associated with an increased rate of diabetes remission. ${ }^{4}$ In obese individuals with type 2 diabetes, bariatric surgery can be associated with remission of type 2 diabetes in around $80 \%$ cases. $^{2,3}$ The use of bariatric in type 1 diabetes is associated with decreased weight, improvement in glycated HbA1c level, and insulin dose reduction (high dose of insulin can be challenging to be administered in cases of gross obesity). ${ }^{5}$ Different types of bariatric surgery are used, but the

published online June 28, 2021
DOI https://doi.org/

$10.1055 / \mathrm{s}-0041-1731139$ ISSN 0974-2727 most commonly performed bariatric surgeries are Roux-en-Y gastric bypass (RYGB) and sleeve gastrectomy. This involves resecting part of the stomach and intestine and subsequently repositioning part of the intestine. ${ }^{1-4}$ This can be associated with deficiency of micronutrients, including iron, folate, vitamin $B_{1}$, vitamin $B_{12}$, zinc, vitamin $D$, and calcium. ${ }^{6}$ Therefore, individuals who have bariatric surgery performed will need dedicated and specialist nutritional support by dietician and metabolic physician to monitor and diagnose deficiencies of vitamins, trace elements, and minerals. In this case report we highlight the important of replacement of thiamine in individuals with diabetes and bariatric surgery.

\section{Case Presentation}

A 29-year-old woman presented with general malaise, abdominal pain, and hyperketonemia. She has a background of type 1 diabetes, hypothyroidism, and morbid obesity. She was diagnosed with type 1 diabetes at the age of 4 years. (c) 2021. The Indian Association of Laboratory Physicians.

This is an open access article published by Thieme under the terms of the Creative Commons Attribution-NonDerivative-NonCommercial-License, permitting copying and reproduction so long as the original work is given appropriate credit. Contents may not be used for commercial purposes, or adapted, remixed, transformed or built upon. (https://creativecommons.org/licenses/by-nc-nd/4.0/).

Thieme Medical and Scientific Publishers Pvt. Ltd. A-12, 2nd Floor, Sector 2, Noida-201301 UP, India 
During adolescence, she had significant weight gain and fatigue which subsequently led to a diagnosis of hypothyroidism. Six weeks prior to presentation, she had undergone a gastric bypass surgery. Immediately after the bariatric surgery, she was admitted with severe diabetic ketoacidosis (DKA) which required intensive treatment unit (ITU) admission. Computed tomography (CT) scan of the abdomen during admission showed no evidence of postoperative complications (-Fig. 1). After discharge, she notably had significantly and persistently raised ketones: typically 3 to $5 \mathrm{mmol} / \mathrm{L}$ in the morning, which gradually improved during a day. She lost $16 \mathrm{~kg}$ in the 6 weeks following surgery.

On this admission, she had worsening abdominal pain, limited oral intake, and general malaise. She reported no focal symptoms of infection. In the days prior to admission,

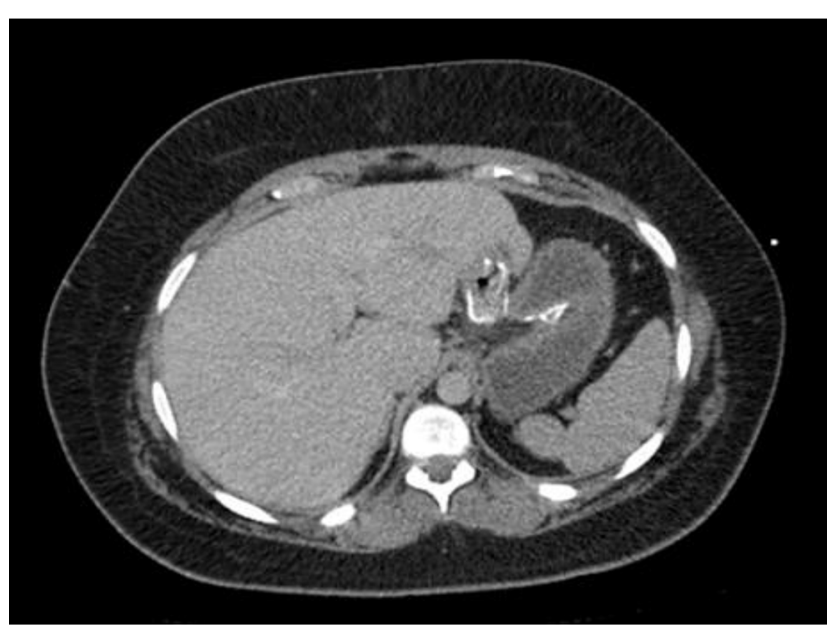

Fig. 1 Post gastric bypass computed tomography (CT) abdomen pelvis with contrast, demonstrating gastrojejunal anastomosis intact following bariatric surgery. she had noted that the previous pattern of raised morning ketones had switched to a pattern of persistent elevation throughout the day. She had continued her regular basal insulin regime and had adjusted her bolus doses appropriately for her oral intake. She was taking 8 units of tresiba in the evening, with 1 unit/10 g carbohydrate of NovaRapid with meals. Aside from insulin, she was only taking $175 \mu \mathrm{g}$ levothyroxine once daily. On examination, she was afebrile, with respiratory rate of 16 and regular comfortable respiratory effort. Her blood pressure was $110 / 60$ and she had a heart rate of 86 . She had a Glasgow Coma Scale (GCS) of 15 . Her abdomen was soft and nontender. On admission, she a capillary blood glucose of $13.3 \mathrm{mmol} / \mathrm{L}$, ketones $4.5 \mathrm{mmol} / \mathrm{L}$, and $\mathrm{pH} 7.267$. She had a normal inflammatory marker (CRP $9.3 \mathrm{mg} / \mathrm{L}$ and WCC of $8 \times$ $109 / \mathrm{L}$ ) and normal renal and liver function. She was treated according to the local DKA regimen. $\mathrm{pH}$, ketone, and glucose improved until they were in the normal range (-Table 1, -Fig. 1). However, when she was transitioned onto her regular insulin regime, her ketones quickly increased again to $3 \mathrm{mmol} / \mathrm{L}$. Empirical, thiamine $50 \mathrm{mg}$ once daily supplementation began on day 2 of admission. Following starting thiamine supplementation her ketones remained controlled and remained low $(<0.5 \mathrm{mmol} / \mathrm{L})(-$ Fig. 2 ). In the subsequent weeks following this admission, we monitored her ketones daily and noted these remained extremely well controlled (0.01-0.1 mmol/L). She had no further episodes of ketoacidosis or DKA in the following 4 months. The patient gave consent for publication of the case report.

\section{Discussion}

In this case report, we have shown that thiamine replacement is associated with normalization of plasma ketones in individuals with type 1 diabetes and bariatric surgery following

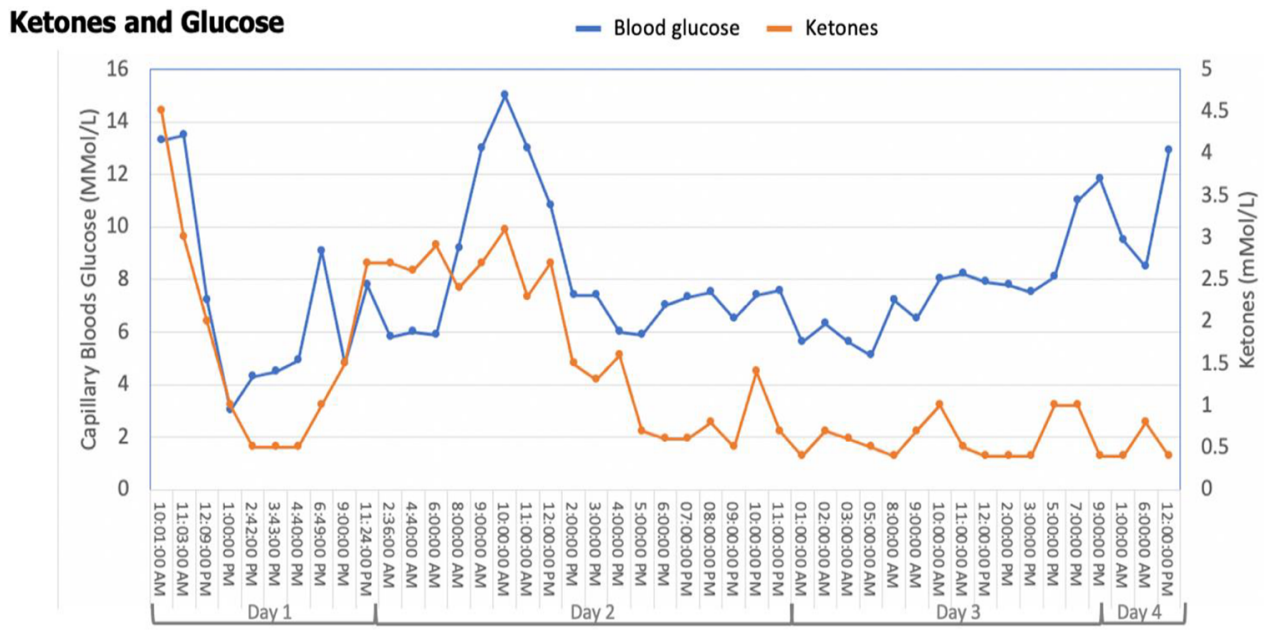

VRII

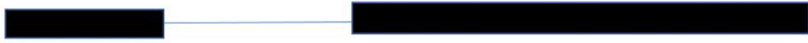

Thiamine supplementation

Fig. 2 Levels of plasma glucose and ketone before and after thiamine replacement. Importantly, thiamine replacement (started on day 2) was associated with normalization of plasma ketones level, and this period is seen in the figure within those black square dots. 
Table 1 Improvement in $\mathrm{pH}$ (thiamine administration started on day 2)

\begin{tabular}{|c|c|c|c|c|c|}
\hline & Day 1 (10 a.m. admission) & $\begin{array}{l}\text { Day } 1 \\
\text { (1 p.m.) }\end{array}$ & $\begin{array}{l}\text { Day } 2 \\
\text { (6 a.m.) }\end{array}$ & $\begin{array}{l}\text { Day } 2 \\
\text { (10 p.m.) }\end{array}$ & $\begin{array}{l}\text { Day } 3 \\
\text { (3 p.m.) }\end{array}$ \\
\hline $\mathrm{pH}$ & 7.267 & 7.30 & 7.34 & 7.359 & 7.45 \\
\hline $\mathrm{HCO}_{3}$ & 20.3 & 21.3 & 18.1 & 20.0 & 23.0 \\
\hline $\mathrm{CO}_{2}$ & 6.0 & 5.5 & 4.5 & 4.8 & 4.5 \\
\hline $\mathrm{Na}^{+}$ & 135 & 138 & 137 & 134 & 135 \\
\hline $\mathbf{K}^{+}$ & 3.8 & 2.9 & 3.5 & 2.77 & 3.0 \\
\hline
\end{tabular}

an episode of DKA. Importantly, Adnan et al showed that thiamine levels were decreased in individuals with type 1 and type 2 diabetes and this may be a result of increased loss of thiamine in urine. ${ }^{7}$ The main function of thiamine is to act as cofactor of several enzymes important for carbohydrate (transketolase [TKT], pyruvate dehydrogenase, and $\alpha$-ketoglutarate dehydrogenase) and amino acid (branched-chain $\alpha$-keto acid dehydrogenase) metabolism. ${ }^{8}$ Therefore, it has been suggested that individuals with diabetes will benefit from taking thiamine supplement. Importantly, thiamine deficiency can lead to high plasma ketones level in individuals with type 1 diabetes. ${ }^{8}$ Interestingly, a clinical trial is in progress to assess whether thiamine replacement should be part of the protocol of DKA, which is expected to be completed by April 2023. ${ }^{9}$ The half-life of thiamine is 9 to 18 days and deficiency may result from excess renal loss or excess alcohol intake. There are two methods for measurement of thiamine by the laboratory and this may require referral of the sample to the reference laboratory. ${ }^{8}$ Therefore, we have elected to treat the patient with thiamine rather than wait for the result from reference laboratory, which may take at least 3 weeks.

Importantly, several reports have shown the association between thiamine deficiency and bariatric surgery. For instance, Tang et al showed that in cohort of 147 patients with bariatric surgery $25.7 \%$ had thiamine deficiency. Independent risk factors associated with thiamine deficiency were being African American, a larger preoperative body mass index (BMI), and self-reported repetitive episodes of nausea and vomiting. ${ }^{10}$ Malone showed in a review article for data published within 20 years that bariatric surgery can be associated with thiamine deficiency. ${ }^{11}$ Different case reports showed that thiamine deficiency can be severe with bariatric surgery to the extent that patients may present with Wernicke encephalopathy. ${ }^{12-14}$

Importantly, the level of thiamine is also noted to be low in obese individuals with intention to have bariatric surgery. ${ }^{15,16}$ Therefore, it is plausible to suggest that in our patient different factors have contributed to the need for thiamine replacement; among them are diabetes, obesity, and bariatric surgery. Ultimately, this may have resulted in persistent high plasma ketones level since she had the bariatric surgery.

\section{Contribution}

All authors contributed equally in the manuscript.

\section{Conflict of Interest}

None declared.

\section{References}

1 Hafeez S, Ahmed MH. Bariatric surgery as potential treatment for nonalcoholic fatty liver disease: a future treatment by choice or by chance? J Obes 2013;2013:839275

2 Sjöström L, Narbro K, Sjöström CD, et al. Swedish Obese Subjects Study. Effects of bariatric surgery on mortality in Swedish obese subjects. N Engl J Med 2007;357(8):741-752

3 Sjöström L, Peltonen M, Jacobson P, et al. Bariatric surgery and long-term cardiovascular events. JAMA 2012;307(1):56-65

4 Park CH, Nam SJ, Choi HS, et al. Korean Research Group for Endoscopic Management of Metabolic Disorder and Obesity. Comparative efficacy of bariatric surgery in the treatment of morbid obesity and diabetes mellitus: a systematic review and network meta-analysis. Obes Surg 2019;29(7):2180-2190

5 Ichikawa $\mathrm{H}$, Imoto $\mathrm{H}$, Tanaka $\mathrm{N}$, et al. Efficacy of laparoscopic sleeve gastrectomy for patient with morbid obesity and type 1 diabetes mellitus: a case report. Surg Case Rep 2021;7(1):7

6 Lange J, Königsrainer A. Malnutrition as a complication of bariatric surgery-a clear and present danger? Visc Med 2019;35(5):305-311

7 Anwar A, Ahmed Azmi M, Siddiqui JA, Panhwar G, Shaikh F, Ariff M. Thiamine level in type I and type II diabetes mellitus patients: a comparative study focusing on hematological and biochemical evaluations. Cureus 2020;12(5):e8027

8 Pácal L, Kuricová K, Kaňková K. Evidence for altered thiamine metabolism in diabetes: is there a potential to oppose gluco- and lipotoxicity by rational supplementation? World J Diabetes 2014;5(3):288-295

9 US National Library of Medicine. Thiamine as adjunctive therapy for diabetic ketoacidosis. available at: https://clinicaltrials.gov/ct2/show/NCT03717896. Published October 24, 2018. Accessed February 18, 2021.

10 Tang L, Alsulaim HA, Canner JK, Prokopowicz GP, Steele KE. Prevalence and predictors of postoperative thiamine deficiency after vertical sleeve gastrectomy. Surg Obes Relat Dis 2018;14(7):943-950

11 Malone M. Recommended nutritional supplements for bariatric surgery patients. Ann Pharmacother 2008;42(12):1851-1858

12 Saab R, El Khoury M, Farhat S. Wernicke's encephalopathy three weeks after sleeve gastrectomy. Surg Obes Relat Dis 2014;10(5):992-994

13 Zafar A. Wernicke's encephalopathy following Roux en Y gastric bypass surgery. Saudi Med J 2015;36(12):1493-1495

14 Arnadottir LO, Sigurbjornsson S, Gudbjartsson T. Beriberi 10 years after gastric bypass surgery-case report. Laeknabladid 2016;102(11):497-499

15 Albaugh VL, Williams DB, Aher CV, Spann MD, English WJ. Prevalence of thiamine deficiency is significant in patients undergoing primary bariatric surgery. Surg Obes Relat Dis 2020; $1550-7289(20): 30706-1$

16 Carrodeguas L, Kaidar-Person O, Szomstein S, Antozzi P, Rosenthal R. Preoperative thiamine deficiency in obese population undergoing laparoscopic bariatric surgery. Surg Obes Relat Dis 2005;1(6):517-522, discussion 522 